\title{
SPEED-SENSORLESS VECTOR CONTROLLED INDUCTION MOTOR DRIVE TAKING SATURATION INTO ACCOUNT
}

\author{
A. M. El-Sawy, Yehia S. Mohamed and A. A. Zaki \\ Electrical Engineering Department, Faculty of Engineering, \\ El-Minia University, EL-Minia, Egypt. \\ engahmedz@yahoo.com
}

(Received April 4, 2009 Accepted August 20, 2009).

\begin{abstract}
This paper aims to develop a speed sensorless indirect vector controlled induction motor drive taking the effect of magnetic flux saturation into account. A mathematical dynamic model of an induction motor as influenced by magnetic circuit saturation is presented. Moreover, a modified structure of indirect vector controller scheme is proposed which involves the saturated value of the magnetizing scheme. In this scheme, an effective method for rotor speed estimation is based on a modified model reference adaptive system (MRAS) to achieve high-precise control in a wide range of motor speed. The online magnetizing inductance estimation algorithm is used to modify the value of the magnetizing inductance which is used in the motor speed estimator. Digital simulations have been carried out in order to evaluate the effectiveness of the proposed sensorless drive system. The results have proven excellent steady-state and dynamic performances of the drive system, which confirms the validity of the proposed scheme.
\end{abstract}

\section{LIST OF SYMBOLS}

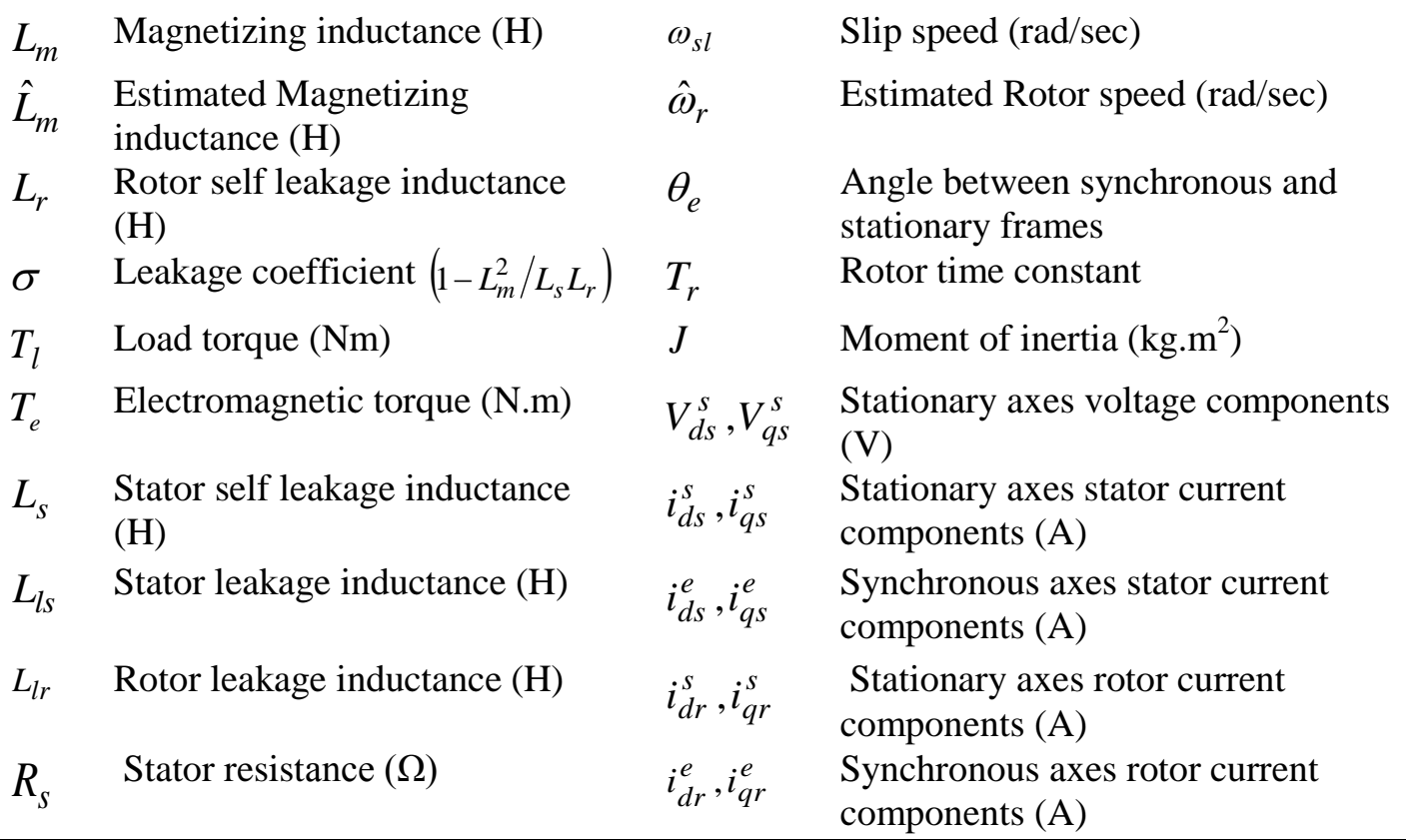




\begin{tabular}{|llll|}
\hline$R_{r}$ & Rotor resistance $(\Omega)$ & $\lambda_{d r}^{s}, \lambda_{q r}^{s}$ & $\begin{array}{l}\text { Stationary axes rotor flux components } \\
(\mathrm{wb})\end{array}$ \\
$\omega_{e}$ & Synchronous speed $(\mathrm{rad} / \mathrm{sec})$ & $\hat{\lambda}_{d r}^{s}, \hat{\lambda}_{q r}^{s}$ & $\begin{array}{l}\text { Stationary axes estimated rotor flux } \\
\text { components }(\mathrm{wb})\end{array}$ \\
$\omega_{e}^{*}$ & $\begin{array}{l}\text { Command synchronous speed } \\
(\mathrm{rad} / \mathrm{sec})\end{array}$ & $\lambda_{d m}^{s}, \lambda_{q m}^{s}$ & $\begin{array}{l}\text { Stationary axes magnetizing flux } \\
\text { components }(\mathrm{wb})\end{array}$ \\
$\omega_{r}$ & Actual Rotor speed $(\mathrm{rad} / \mathrm{sec})$ & $p=d / d t$ & Differential operator
\end{tabular}

\section{INTRODUCTION}

The vector control principle provides great flexibility for the control of induction motor drives. However, it is costly to implement because of the need for a shaft speed sensor. Also, this sensor reduces the reliability of the control system. The speed sensor may be eliminated if the speed could be estimated using the machine terminal voltages and currents.

Several methods have been recently, proposed for speed estimation of high performance induction motor drives. Some of these methods are based on a non-ideal phenomenon such as rotor slot harmonics [1]. Such methods require spectrum analysis, which besides being time consuming procedures; they allow a narrow band of speed control. Another class of algorithms relies on some kind of probing signals injected into stator terminals (voltage and/or current) to detect the rotor flux and consequently, the motor speed [2]. These probing signals, sometimes, introduce a high frequency torque pulsations, and hence speed ripple. In some cases a useful data may be distorted due to interference with the high frequency probing signals. Despite the merits of the above methods of speed estimation near zero speed, they suffer from large computation time, complexity and limited bandwidth control.

Alternatively, speed information can be obtained by using the machine model and its terminal quantities, like voltage and current. These include different methods such as the use of simple open loop speed calculators [3]; Model Reference Adaptive Systems (MRAS) [4-6]; Extended Kalman Filters [7]: Adaptive Flux Observer [8]; Artificial Intelligence Techniques [9]; and Sliding Mode Observer (SMO) [10]. These methods exhibit accurate and robust speed estimation performance; however they are highly dependent on the machine parameters [11]. The method that depends on MRAS techniques has a main advantage from these methods, that is; it is rather simple to implement and uses minimum processor time and memory.

In many variable torque applications, it is desirable to operate the machine under magnetic saturation to develop higher torque [12]. The magnetizing inductance value is varied nonlinearly according to the saturation. Also, many applications such as spindle and gearless traction drives require a wide speed range, with the maximum required speed that considerably exceeds the motor rated speed. Speed estimation in the field weakening region presents redoubtable difficulties regardless of the method used for the speed estimation. Therefore, accurate speed estimation using model-based approaches is possible only, if the speed estimation algorithm modified in such a way that the variation of main flux saturation is recognized within the estimator. Accurate value of magnetizing inductance is of importance for many reasons. The first one is the 
correct setting of the d-axis stator current reference in a vector controlled drive which requires the accurate magnetizing inductance value to be known. The second one is the accurate speed estimation, using machine model-based approaches, of a sensorless vector controlled drive for operation in the field weakening region. The third reason is the dependency of rotor time constant identification schemes on the magnetizing inductance. The accurate estimation of rotor time constant in the field weakening region requires that the value of the magnetizing inductance to be known correctly [12].

Many researches have been devoted to yielding speed estimation of the field oriented controlled induction motor considering a constant value of the magnetizing inductance. However, there are some of the methods which studied the magnetizing inductance variation due to saturation or flux level variation on the machine. The method used in [12-13] depends on measured stator voltages and currents and the magnetizing curve of the machine and this method had also been used in [16] but with sliding mode observer for speed estimation. In [14-15], the performance of vector controlled induction motor drives had been investigated as influenced by magnetic saturation and its compensation but the rotor speed is assumed to be measured by speed sensor.

In this paper, speed sensorless vector controlled induction motor drives taking saturation into account has been presented. Mathematical models of an induction motor as influenced by magnetic saturation and saturated indirect vector controller have been presented. The modified model reference adaptive system has been used to estimate the rotor speed to eliminate the speed sensor. The rotor speed estimation algorithm requires the knowledge of magnetizing inductance which varies with saturation level in the machine so it has been modified with an online magnetizing inductance estimator. The magnetizing inductance estimation has been developed depending on the measured stator voltages and currents and the magnetizing curve of the induction motor.

\section{DYNAMIC MODEL OF INDUCTION MOTOR AS INFLUENCED BY MAGNETIC CIRCUIT SATURATION}

To accommodate the effect of magnetic-circuit saturation, the dynamic model of the induction motor in the stationary $d^{s}-q^{s}$ reference frame [13]-[15] has been modified to include the saturation of the main flux path as follows:

$$
\begin{aligned}
& \frac{d i_{d s}^{s}}{d t}=\frac{1}{L_{d s}}\left[V_{d s}^{s}-R_{s} i_{d s}^{s}-L_{2 s} \frac{d i_{q s}^{s}}{d t}-L_{d m} \frac{d i_{d r}^{s}}{d t}-L_{2 s} \frac{d i_{q r}^{s}}{d t}\right] \\
& \frac{d i_{q s}^{s}}{d t}=\frac{1}{L_{q s}}\left[V_{q s}^{s}-L_{2 s} \frac{d i_{d s}^{s}}{d t}-R_{s} i_{q s}^{s}-L_{2 s} \frac{d i_{d r}^{s}}{d t}-L_{q m} \frac{d i_{q r}^{s}}{d t}\right] \\
& \frac{d i_{d r}^{s}}{d t}=\frac{1}{L_{d r}}\left[-L_{d m} \frac{d i_{d s}^{s}}{d t}-\left(L_{2 s} \frac{d}{d t}+\omega_{r} L_{m}\right) i_{q s}^{s}-R_{r} i_{d r}^{s}-\left(L_{2 s} \frac{d}{d t}+\omega_{r} L_{d r}\right) i_{q r}^{s}\right] \\
& \frac{d i_{q r}^{s}}{d t}=\frac{1}{L_{q r}}\left[-\left(L_{2 s} \frac{d}{d t}-\omega_{r} L_{m}\right) i_{d s}^{s}-L_{q m} \frac{d i_{q s}^{s}}{d t}-\left(L_{2 s} \frac{d}{d t}-\omega_{r} L_{q r}\right) i_{d r}^{s}-R_{r} i_{q r}^{s}\right]
\end{aligned}
$$


The stator and rotor mutual inductance in the d-and q-axes in the above equations are expressed as:

$$
L_{d m}=L_{0}+L_{2 c}, \quad L_{q m}=L_{0}-L_{2 c}
$$

The stator and rotor self inductances in the $\mathrm{d}$ - and q-axes defined in equations (1)-(4) are given by:

$$
\begin{aligned}
& L_{d s}=L_{l s}+L_{d m}, \quad L_{d r}=L_{l r}+L_{d m} \\
& L_{q s}=L_{l s}+L_{q m}, L_{q r}=L_{l r}+L_{q m}
\end{aligned}
$$

Where

$L_{2 c}=L_{2} \cos (2 \mu), L_{2 s}=L_{2} \sin (2 \mu)$

$L_{0}=\frac{L+L_{m}}{2}, L_{2}=\frac{L-L_{m}}{2}$

$L=d\left|\lambda_{m}\right| / d\left|i_{m}\right|$ is a dynamic mutual inductance equal to the first derivative of the magnetization curve. $L_{m}=\left|\lambda_{m}\right| /\left|i_{m}\right|$ is a static mutual inductance and can also be obtained directly from the magnetization curve. Evidently both $L$ and $L_{m}$ take account of the fact that $i_{m}$ is continuously changing in time. And $\mu$ is the angle of the magnetizing current space vector with respect to the reference axis.

The electromagnetic torque can be expressed as:

$$
T_{e}=\frac{3}{2} \frac{P}{2} L_{m}\left(i_{q s}^{s} i_{d r}^{s}-i_{d s}^{s} i_{q r}^{s}\right)
$$

The equation of the motion is:

$$
J \frac{d \omega_{r}}{d t}+f_{d} \omega_{r}+T_{l}=T_{e}
$$

Where $J$ is the inertia of the rotating parts, $f_{d}$ is the damping coefficient of the load and $T_{l}$ is the shaft load torque. The state form of equation (6) can be written as:

$$
\frac{d \omega_{r}}{d t}=\frac{T_{e}-f_{d} \omega_{r}-T_{L}}{J}
$$

Thus the dependent variables of the system are $i_{d s}^{s}, i_{q s}^{s}, i_{d r}^{s}, i_{q r}^{s}$ and $\omega_{r}$. The derivatives of these variables are functions of the variables themselves, motor parameters and stator supply voltage. Simultaneous integration of equations (1)-(5) and (7) predicts the temporal variation of these variables.

\section{SATURATED INDIRECT VECTOR CONTROLLER OF THE INDUCTION MOTOR}

The estimation of rotor flux value and its phase angle is performed in rotor flux oriented $d^{e}-q^{e}$ synchronously rotating reference frame based on stator currents and speed measurement. The rotor flux calculator is derived in such a way that nonlinear relationship between the main flux and magnetizing current is taken into account. In this calculation, the field orientation is maintained, the condition $\lambda_{q r}=0$ is satisfied, 
the influence of q-axis magnetizing flux on resultant magnetizing flux can be neglected $\left(\lambda_{q m}=0\right)$.

The approximate saturated rotor flux calculator is given with:

$\lambda_{d m}=\frac{L_{l r}}{R_{r}} \frac{d \lambda_{r}}{d t}+\lambda_{r}$

$\omega_{s l}=\frac{L_{m}}{T_{r}} \frac{i_{q s}^{e}}{\lambda_{r}}$

$\lambda_{d m}=\lambda_{r}+L_{l r}\left[i_{d s}^{e}-i_{d m}\left(\lambda_{m}\right)\right]$

$T_{e}=\frac{3}{4} P \frac{L_{m}}{L_{r}} i_{q s}^{e} \lambda_{r}$

The simplified saturated indirect vector controller can be constructed as shown in Fig. 1 the scheme is described with the following equations:

$$
\begin{aligned}
& \lambda_{m} \approx \lambda_{d m}=\frac{L_{l r}}{R_{r}} \frac{d \lambda_{r}^{*}}{d t}+\lambda_{r}^{*} \\
& i_{d s}^{e^{*}=i_{d m}}\left(\lambda_{m}\right)+\frac{1}{R_{r}} \frac{d \lambda_{r}^{*}}{d t} \\
& i_{q s}^{e^{*}}=\frac{4}{3 P} \frac{\left(L_{l r}+L_{m}\right)}{L_{m}} \frac{T_{e}^{*}}{\lambda_{r}^{*}} \\
& \omega_{s l}^{*}=\frac{L_{m}}{T_{r}} \frac{i_{q s}^{e^{*}}}{\lambda_{r}^{*}} \\
& \theta_{e}^{*}=\int\left(\omega_{r}+\omega^{*}{ }_{s l}\right) d t
\end{aligned}
$$

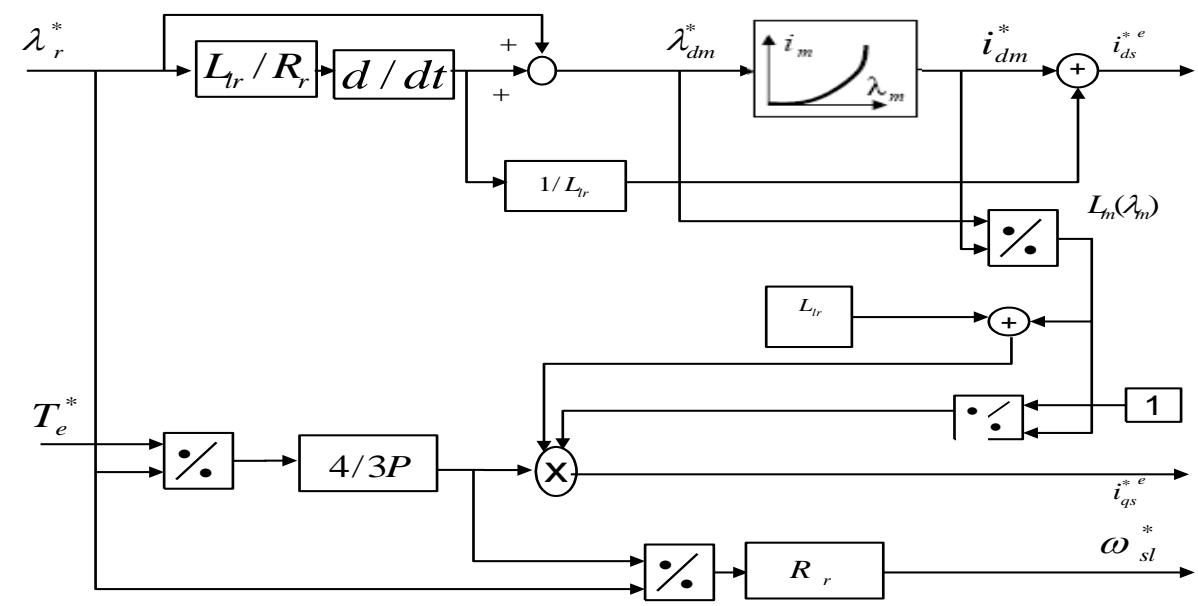

Figure 1: Saturated indirect vector controller scheme 


\section{ROTOR SPEED ESTIMATION BASED ON MRAS}

In vector control schemes, the detection of rotor speed is necessary for calculating the field angle and establishing the outer feedback-loop of speed. Recently, the elimination of speed sensor has been one of the important requirements in vector control schemes because the speed sensor spoils the ruggedness, reliability and simplicity of induction motor drives. Also, the speed sensor can not be mounted in some cases such as motor drives in a hostile environment and high speed motor drives. This is on the expense of adding a speed estimator in the vector control scheme. A number of schemes based on motor models have been derived to estimate the speed of the induction motor from the measured terminal quantities for speed control purpose. In this paper, because the simplicity of the MRAS speed estimators schemes and it uses minimum processor time and memory, the MRAS techniques used to estimate the rotor speed. In order to obtain an accurate estimation of rotor speed, it is necessary to base the estimation on the coupled circuit equations of the motor. The equations for an induction motor in the stationary $d^{s}-q^{s}$ reference frame can be expressed as:

Voltage model (stator equation):

$$
p\left[\begin{array}{l}
\lambda_{d r}^{s} \\
\lambda_{q r}^{s}
\end{array}\right]=\frac{\left(L_{m}+L_{l r}\right)}{L_{m}}\left(\left[\begin{array}{cc}
V_{d s}^{s} \\
V_{q s}^{s}
\end{array}\right]-\left[\begin{array}{lc}
R_{s}+\sigma L_{s} & 0 \\
0 & R_{s}+\sigma\left(L_{m}+L_{l s}\right)
\end{array}\right]\left[\begin{array}{l}
i_{d s}^{s} \\
i_{q s}^{s}
\end{array}\right]\right)
$$

Current model (rotor equation):

$$
p\left[\begin{array}{l}
\lambda_{d r}^{s} \\
\lambda_{q r}^{s}
\end{array}\right]=\left[\begin{array}{cc}
-\frac{R_{r}}{L_{r}} & -\omega_{r} \\
\omega_{r} & -\frac{R_{r}}{L_{r}}
\end{array}\right]\left[\begin{array}{l}
\lambda_{d r}^{s} \\
\lambda_{q r}^{s}
\end{array}\right]+\frac{L_{m}}{T_{r}}\left[\begin{array}{l}
i_{d s}^{s} \\
i_{q s}^{s}
\end{array}\right]
$$

Figure 2 indicate an alternative way of estimating the rotor speed by using the MRAS techniques. Two independent observers are constructed to estimate the components of rotor flux vector, one based on equation (17) and the other based on equation (18). Since (17) does not involve the quantity $\omega_{r}$, this observer may be regarded as a reference model of the induction motor, and (18) which dose involve $\omega_{r}$, may be regarded as an adjustable model. The error between the states of the two models is then used to drive a suitable adaptation mechanism which generates the estimated rotor speed $\omega_{r}$ for the adjustable model until good tracking of the estimated rotor speed to actual one is achieved. For the purpose of deriving an adaptation mechanism, the rotor speed is initially treated as a constant parameter of the reference model. Subtracting (18) for the adjustable model from the corresponding equations for the reference model, the following state error equation can be obtained: 


$$
p\left[\begin{array}{l}
\varepsilon_{d} \\
\varepsilon_{q}
\end{array}\right]=\left[\begin{array}{lr}
-\frac{R_{r}}{L_{r}} & -\omega_{r} \\
\omega_{r} & -\frac{R_{r}}{L_{r}}
\end{array}\right]\left[\begin{array}{l}
\varepsilon_{d} \\
\varepsilon_{q}
\end{array}\right]+\left[\hat{\omega}_{r}-\omega_{r}\right]\left[\begin{array}{l}
-\hat{\lambda}_{q r}^{s} \\
\hat{\lambda}_{d r}^{s}
\end{array}\right]
$$

where

$$
\varepsilon_{d}=\lambda_{d r}^{s}-\hat{\lambda}_{d r}^{s}, \quad \varepsilon_{q}=\lambda_{q r}^{s}-\hat{\lambda}_{q r}^{s}
$$

More ever, equation (19) can be represented in the form:

$$
p[\varepsilon]=[A] \cdot[\varepsilon]-[W]
$$

Since $\omega_{r}$ is a function of the state error, these equations described a non-linear feedback system as indicated in Fig. 3. The hyperstability is assured provided that the linear time-invariant forward-path matrix is strictly positive real and that the nonlinear feedback (which includes the adaptation mechanism) satisfies Popov's criterion for hyperstability [17]. Popov's criterion requires a finite negative limit on the input/output inner product of the feedback system. Satisfying this criterion leads to a candidate adaptation mechanism as follows:

Let $\hat{\omega}_{r}=\left[K_{P}+\frac{K_{I}}{p}\right] \phi(\varepsilon)$

Popov's criterion require that

$$
\int_{0}^{t_{1}}[\varepsilon]^{T}[W] d t \geq-\gamma^{2} \text { For all } t_{1} \geq 0
$$

Where $\gamma^{2}$ is a positive constant. Substituting for $[W]$ and $[\varepsilon]$ in this inequality and using the definition of $\omega_{r}$, Popov's criterion for the present system becomes

$$
\left.\int_{0}^{t_{1}}\left\{\left[\begin{array}{ll}
\varepsilon_{d} & \varepsilon_{q}
\end{array}\right]\left[\begin{array}{c}
-\hat{\lambda}_{q r}^{s} \\
\hat{\lambda}_{d r}^{s}
\end{array}\right]\left(\omega_{r}-\left[K_{P}+\frac{K_{I}}{p}\right] \phi(\varepsilon)\right)\right]\right\} d t \geq-\gamma^{2} \quad \text { For all } t_{1} \geq 0
$$

A solution to this inequality can be found through the following relation:

$\int_{0}^{t_{1}} k(p \cdot f(t)) f(t) d t \geq-\frac{1}{2} k \cdot f(0)^{2}, k>0$

The validity of equation (22) can be verified using inequality equation (23) with an adaptive mechanism equation for rotor resistance identification and can be expressed as:

$$
\hat{\omega}_{r}=\left[K_{P}+\frac{K_{I}}{p}\right]\left(\lambda_{q r}^{s} \hat{\lambda}_{d r}^{s}-\lambda_{d r}^{s} \hat{\lambda}_{q r}^{s}\right)
$$




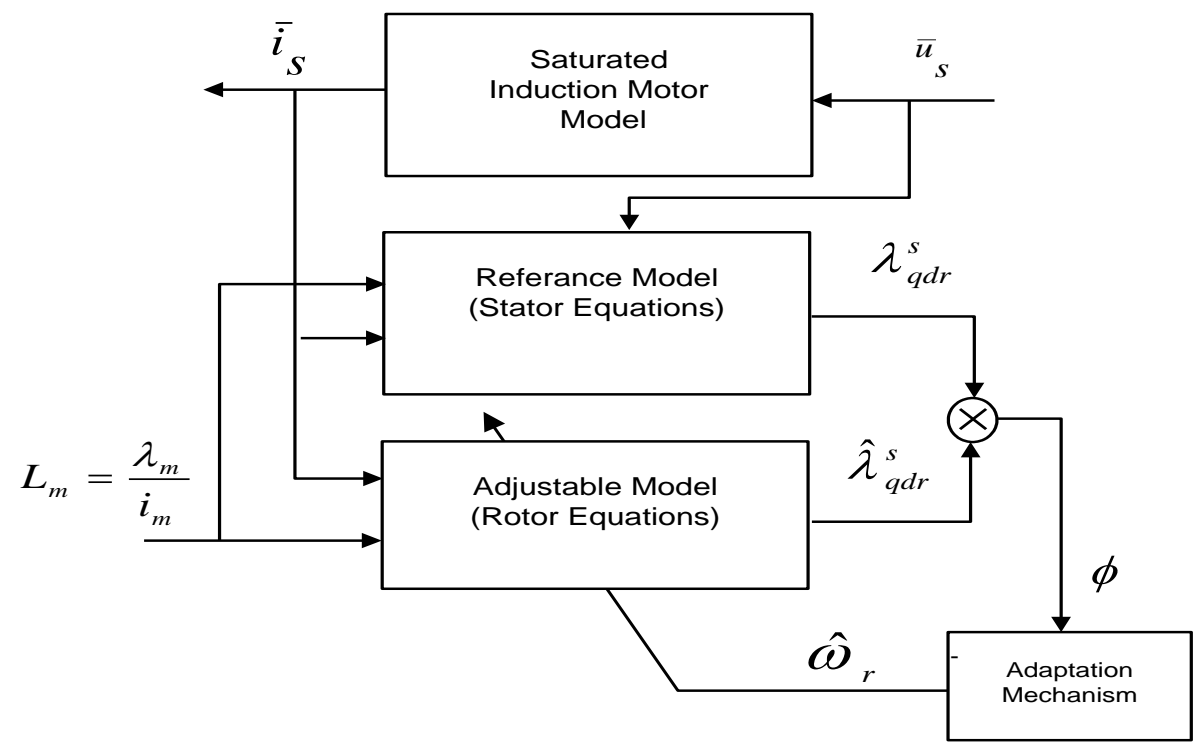

Figure 2: Structure of saturated MRAS system for rotor speed estimation

Linear time-invariant

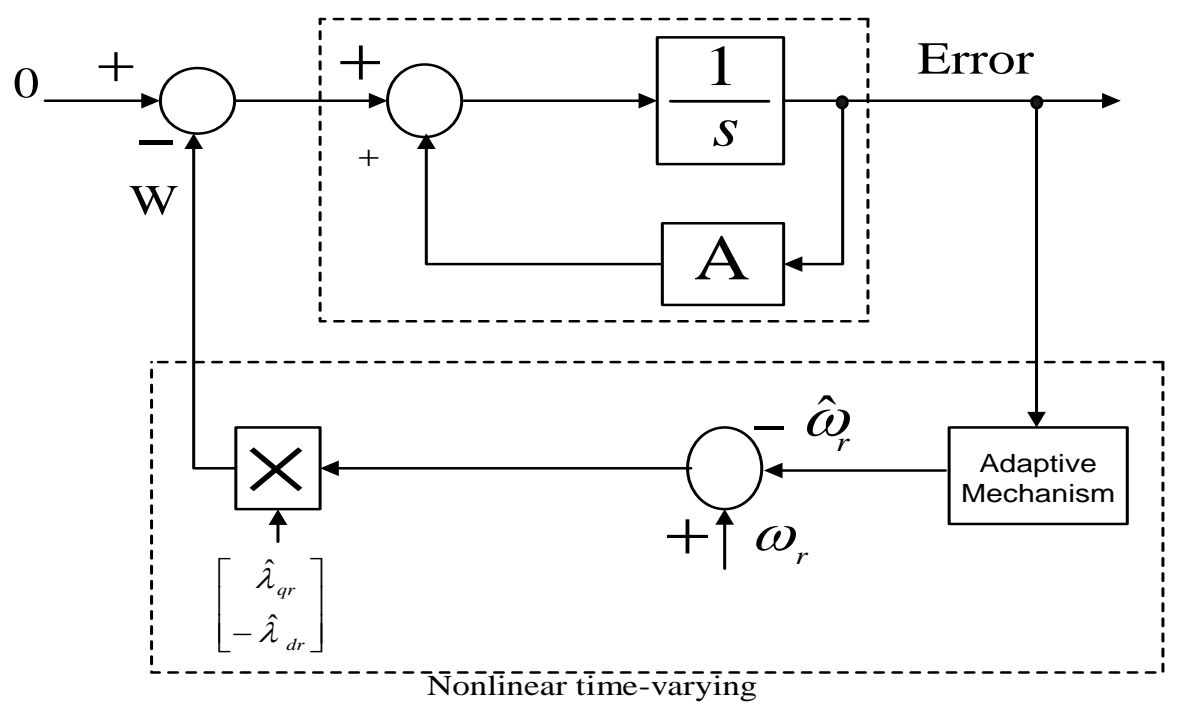

Figure 3: MRAS representation as a nonlinear feedback system

\section{ONLINE IDENTIFICATION ALGORITHM OF MAGNETIZING INDUCTANCE}

The accuracy of rotor speed estimation depends on the precise value of the magnetizing inductance which varies due to the main flux saturation. The magnetizing inductance of an induction motor may vary significantly when the main magnetic flux is saturated. Standard assumption of constant magnetizing inductance is no longer valid and it becomes necessary to compensate for the nonlinear magnetizing inductance 
variation. Therefore, the structure of the speed estimator should be modified in such a way that the variation of main flux saturation is recognized within the speed estimation algorithm by constructing an online magnetizing inductance identification algorithm within the speed estimator [12].

The magnetizing inductance is given on the basis of the known magnetizing curve of the machine with:

$L_{m}=\frac{\lambda_{m}}{i_{m}}$

$\lambda_{m}=\sqrt{\lambda_{d m}^{s}{ }^{2}+\lambda_{q m}^{s}{ }^{2}}$

$\lambda_{d m}^{s}=\int\left(V_{d s}^{s}-R_{s} i_{d s}^{s}\right) d t-L_{l s} i_{d s}^{s}$

$\lambda_{q m}^{s}=\int\left(V_{q s}^{s}-R_{s} i_{q s}^{s}\right) d t-L_{l s} i_{q s}^{s}$

Since the magnetizing flux is known, it is possible to estimate the magnetizing inductance using the known non linear inverse magnetizing curve

$i_{m}=f\left(\lambda_{m}\right)$

$\hat{L}_{m}=\frac{\lambda_{m}}{i_{m}}$

\section{PROPOSED SENSORLESS VECTOR CONTROLLED INDUCTION MOTOR DRIVE}

Figure 4 shows the block diagram of the proposed sensorless indirect vector controlled induction motor drive taking saturation into account. It consists mainly of a loaded induction motor model taking saturation into account, a hysteresis current-controlled PWM (CCPWM) inverter, a saturated vector control scheme followed by a coordinate transformation (CT) and an outer speed loop. In addition to the machine and inverter the system include speed controller, an adaptive motor speed estimator. To compensate the effect of nonlinear magnetizing inductance variation due to magnetic circuit saturation in the accuracy of rotor speed estimation, an online magnetizing inductance estimator has been constructed within the rotor speed estimators. The online magnetizing inductance estimation depends on the measured stator voltages and currents and magnetizing curve of the induction motor. The speed controller generates the command $q^{e}$-components of stator current $i_{q s}^{*^{e}}$ from the speed error between the estimated motor speed and the command speed. The rotor flux reference decreases in inverse proportion to the speed of rotation in the field weakening region, while it is constant and equal to rated rotor flux $\lambda_{r n}$ in the base speed region as also shown in Fig. 4 and is used to feed the saturated vector controller scheme for obtaining the command of stator current $i_{d s}^{*^{e}}$. 
The measurements of two stator phase voltages and currents are transformed to $d^{s}$ - and $q^{s}$ - components and are used in the adaptive rotor speed and online magnetizing inductance estimators. The coordinate transformation (CT) in Fig. 4 is used to transform the stator currents components command $\left(i_{q s}^{*^{e}}\right.$ and $\left.i_{d s}^{*}\right)$ to the three phase stator current command $\left(i_{a s}^{*}, i_{b s}^{*}\right.$ and $\left.i_{c s}^{*}\right)$ by using the field angle $\theta_{e}^{*}$. The hysteresis current control compares the stator current to the actual currents of the machine and switches the inverter transistors in such a way that commanded currents are obtained.

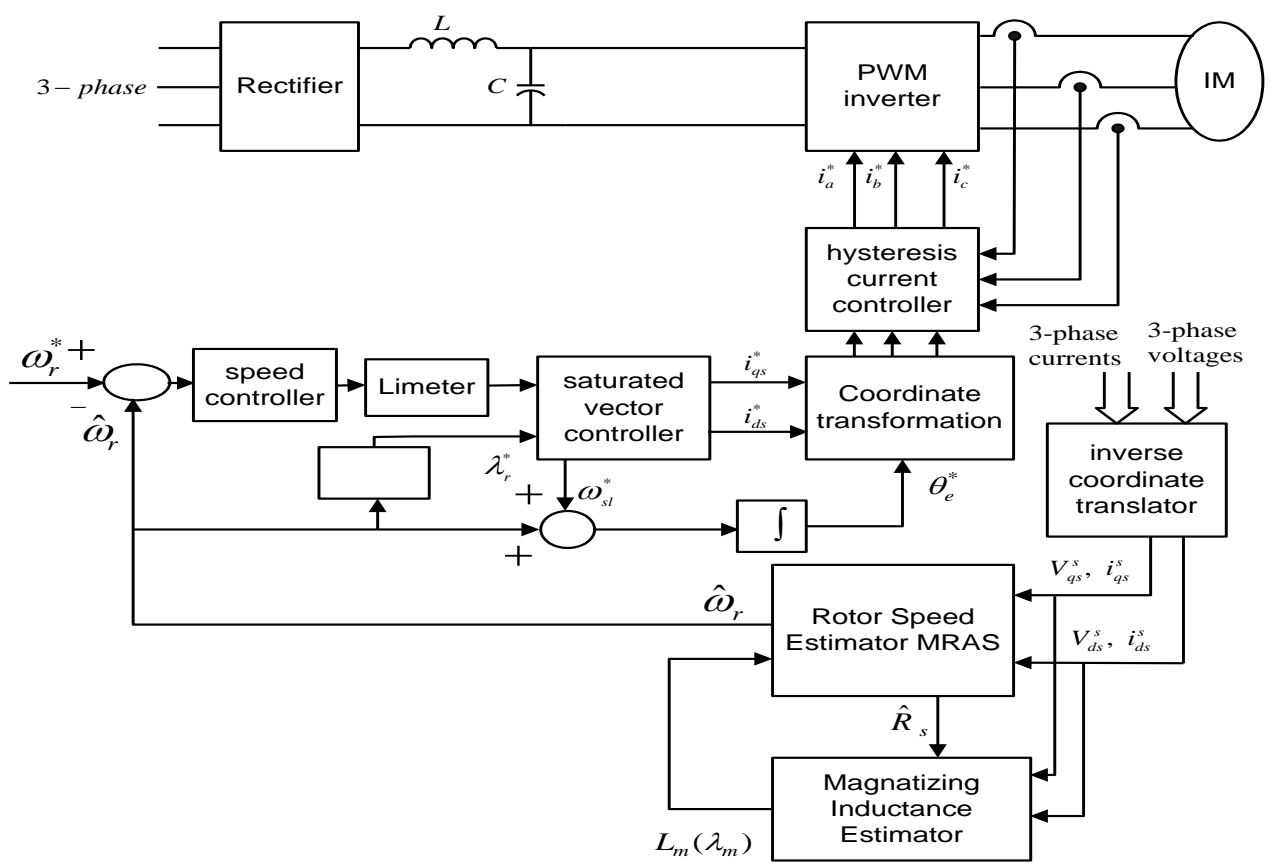

Figure 4: Overall block diagram of the proposed sensorless vector controlled induction motor drive

\section{SIMULATION RESULTS AND DISCUSSIONS}

Computer simulations have been carried out in order to validate the effectiveness of the proposed scheme of Fig. 4. The Matlab / Simulink software package has been used for this purpose.

The induction motor under study is a $3.8 \mathrm{HP}$, four poles motor, whose nominal parameters and specifications are listed in table 1 . The actual value of the magnetizing inductance in the motor model is considered to account for the magnetic circuit saturation as measured in the laboratory. It is represented as a function of the magnetizing current $I_{m}$ by a suitable polynomial in the Appendix 1 . 
Table 1: Parameters and data specifications of the induction motor

\begin{tabular}{|c|c|c|c|}
\hline Rated power $(\mathrm{HP})$ & 3.8 & Rated voltage $(\mathrm{V})$ & 380 \\
\hline Rated current $(\mathrm{A})$ & 8 & Rated frequency $(\mathrm{Hz})$ & 50 \\
\hline $\mathrm{Rs}(\Omega)$ & 1.725 & $\operatorname{Rr}(\Omega)$ & 1.009 \\
\hline $\mathrm{Ls}(\mathrm{H})$ & 0.1473 & $\operatorname{Lr}(\mathrm{H})$ & 0.1473 \\
\hline $\mathrm{Lm}(\mathrm{H})$ & 0.1271 & Rated rotor flux,$(\mathrm{wb})$ & 0.735 \\
\hline $\mathrm{J}\left(\mathrm{kg} \cdot \mathrm{m}^{2}\right)$ & 0.0400 & Rated speed $(\mathrm{rpm})$ & 1450 \\
\hline
\end{tabular}

The transient performance of the proposed sensorless drive system is investigated for step-change of the load torque. Figures 5a, 5b, 5c and $5 d$ show the actual and estimated rotor motor speed, electromagnetic torque, stator phase current and $d^{e}-q^{e}$ axes rotor flux components, when the motor is subject to a load disturbance from 10 to 20 N.m (about rated torque) at $100 \mathrm{rpm}$. Figure 5a shows the dip and overshoot of the estimated motor speed following the application and removal of the load torque disturbance. The speed dip and overshoot are determined by the gains of the speed controller of motor speed loop, as indicated in Fig. 5a. Figure 5b shows fast and good response of the motor torque. However, this torque exhibits highfrequency pulsations of large magnitude due to voltage source inverter pulse width modulation. The rotor flux components are unchanged during the load disturbance as shown in Fig. 5d. This proves that the decoupled control of the torque producing current from the magnetizing current is evident at low speed and with load torque disturbance.

Figure 6 shows the performance of the conventional MRAS speed estimator for speed sensorless induction motor drives when operating in the field weakening region. Figures $6 a, 6 b, 6 c$ and $6 d$ show the actual and estimated motor speed, electromagnetic torque, error between actual and estimated speeds and $d^{e}-q^{e}$ axes rotor flux components, when the motor speed command is changed from $1500 \mathrm{rpm}$ to $1800 \mathrm{rpm}$ in step change fashion at $\mathrm{t}=3$ second. The rotor flux reference decreases in inverse proportion to the speed of rotation in the field weakening region, while it is constant and equal to rated rotor flux in the base speed region. Figure 6a shows that; due to operation in the field weakening region with reduced rotor flux command and using a value of magnetizing inductance in MRAS estimator equals to its nominal value, an error between the estimated speed and actual rotor speed has been found. Also; figure $6 \mathrm{~d}$ shows that there exist steady-state errors between the rotor flux vector and its reference value. These performances can be improved by introducing the proposed control system scheme with using online magnetizing inductance estimation that gives an accurate value of magnetizing inductance at every level of magnetizing flux. 
(a) Estimated and actual speed (rpm)

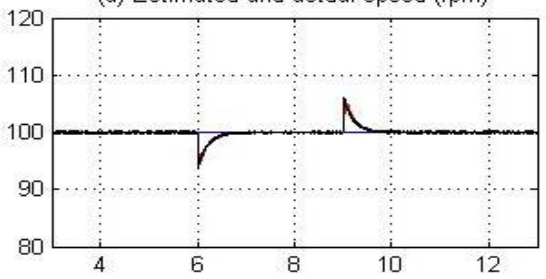

(c) Stator phase current (A)

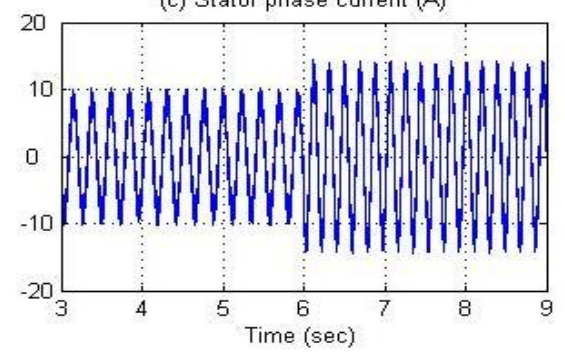

(b) Load and electromagnatic torque (N.m)

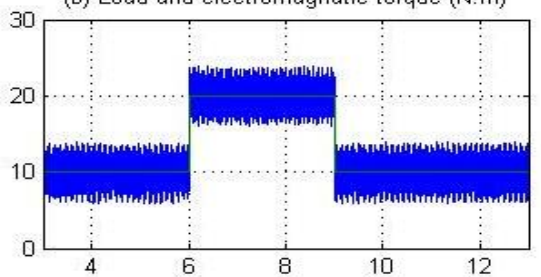

(d) d-q axes rotor flux (wb)

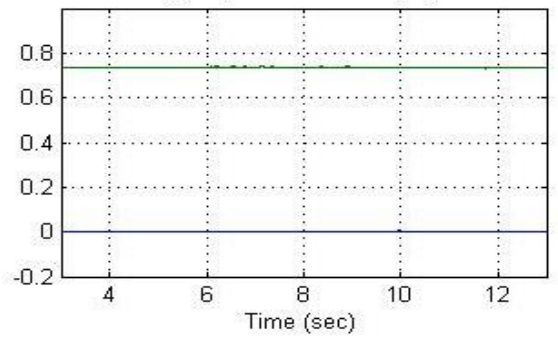

Figure 5: Performance of the proposed sensorless drive system for load torque disturbance.(a) actual and estimated rotor speed, (b) electromagnetic torque, (c) stator phase current and (d) $d^{e}-q^{e}$ axes rotor flux components.

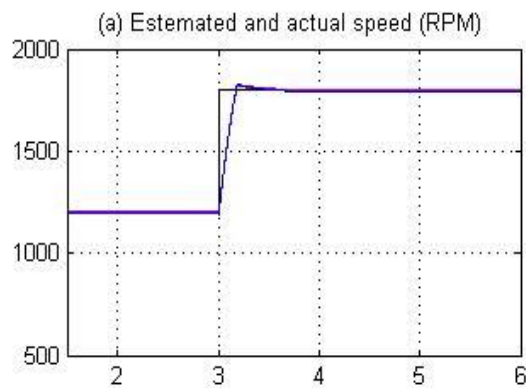

(c) Error (actual speed- estemated speed)(RPM)

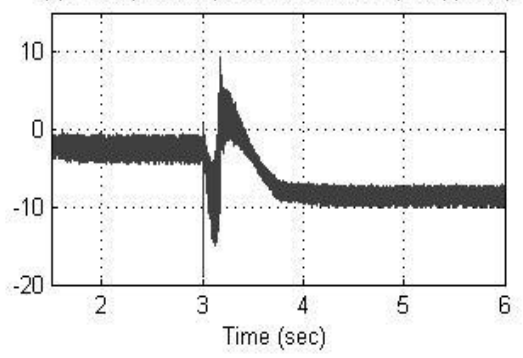

(b) Load and electromagnatic torque ( $\mathrm{Nm}$ )

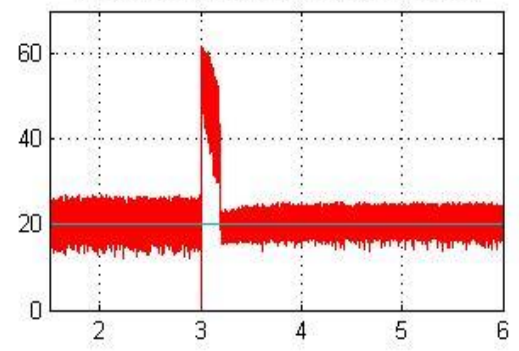

(d) d-q axes rotor flux (Wb)

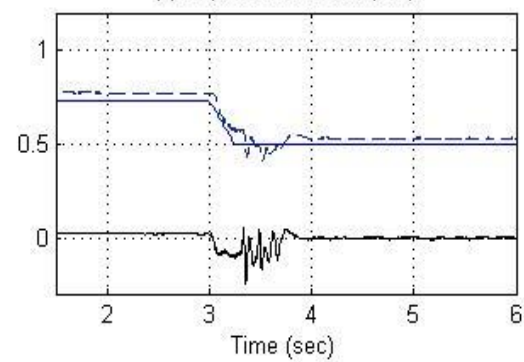

Figure 6: Performance of the conventional sensorless drive system for operation in the field weakening region.(a) actual and estimated and motor speed, (b) electromagnetic torque, (c) error between actual and estimated speeds and (d) $d^{e}-q^{e}$ axes rotor flux components. 
Figure 7 shows the performance of the control system with the proposed MRAS speed estimator. From the figure, the actual and estimated speeds have the same track as shown in Fig 7a. The rotor flux components are taken the same track as commanded value during the field weakening region as shown in Fig.7d. This proves that the decoupled control of the torque producing current from the magnetizing current is evident at speed higher than rated speed with reduced rotor flux command.

(a) Estemated and actual speed (RPM)

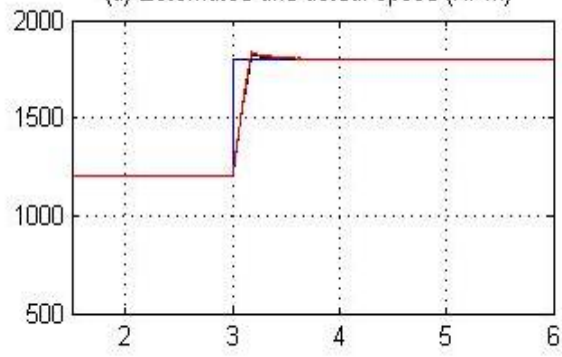

(c) Error (actual speed- estemated speed)(RPM)

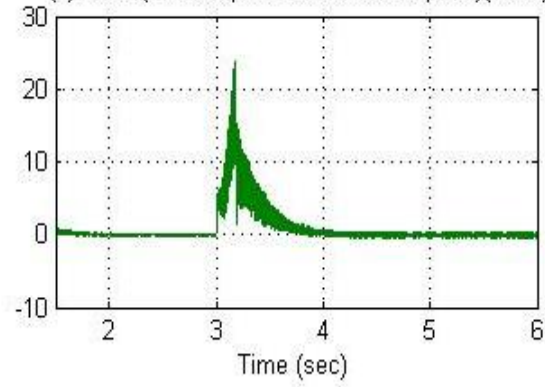

(b) Load and electromagnatic torque $(\mathrm{Nm})$

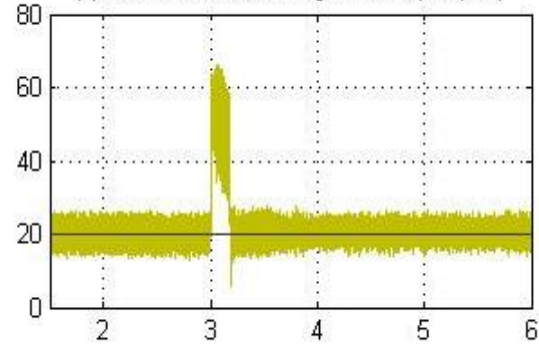

(d) $d-q$ axes rotor flux (Wb)

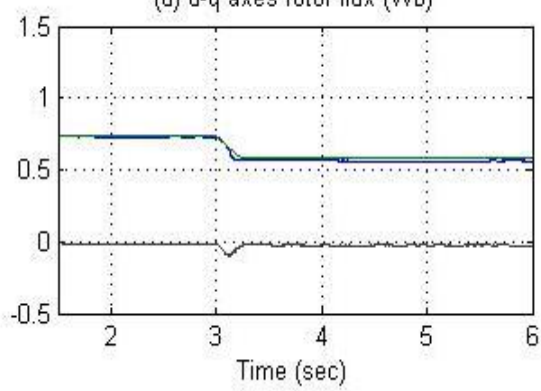

Figure 7: Performance of the proposed sensorless drive system for operation in the field weakening region.(a) actual and estimated and motor speed, (b) electromagnetic torque, (c) error between actual and estimated speeds and (d) $d^{e}-q^{e}$ axes rotor flux components

\section{CONCLUSION}

A MRAS technique for speed estimation of sensorless indirect vector controlled induction motor drives taking saturation into account has been presented. The field orientation principle is used to asymptotically decouple the rotor speed from the rotor flux. The control system has been designed in such a way that the influence of magnetizing inductance variation is eliminated completely. The MRAS estimator has been modified by constructing an online magnetizing inductance estimator within it. The online identification of the magnetizing inductance has been used to eliminate the problem of magnetizing inductance mismatch due to variation of the magnetic flux due to saturation or operation in the field weakening region with reduced the rotor flux command. The online identification algorithm of magnetizing inductance from measured stator voltages and currents enables the correct calculation of magnetizing 
inductance at any operating point and also taking variation in the level of saturation into consideration. Magnetizing inductance, estimated in this way, is further utilized within MRAS, so that the main flux saturation variation is taken in to consideration.

Digital simulations have been carried out in order to validate the effectiveness of the proposed scheme. The simulation results, show the supremacy of the proposed control system with on line identification of magnetizing inductance over the constant parameter one when the induction motor is saturated or in the field weakening region.

\section{Appendix I}

The non-linear relationship between the air-gap voltage and the magnetizing current was measured from no-load test of the induction motor neglecting core losses. Then, the relationship between the magnetic flux and the magnetizing current (i.e. magnetizing curve) has been obtained. The data of the magnetizing curve was fitted by a suitable polynomial which is expressed as:

$$
\lambda_{\mathrm{m}}=0.000011 I_{\mathrm{m}}^{6}-0.00041 I_{\mathrm{m}}^{5}+0.0058_{\mathrm{m}}^{4}-0.037 I_{\mathrm{m}}^{3}+0.082 I_{\mathrm{m}}^{2}+0.15 I_{\mathrm{m}}+0.002 \zeta
$$

The static magnetizing inductance $L_{m}$ is calculated from the above polynomial as $L_{m}=\lambda_{m}\left(I_{m}\right) / I_{m}$ and the dynamic magnetizing inductance $L$ is calculated from the first derivative of this polynomial as $L=d \lambda_{m}\left(I_{m}\right) / d I_{m}$. Figure Appendix I shows the relationship between the magnetizing flux and the magnetizing current.

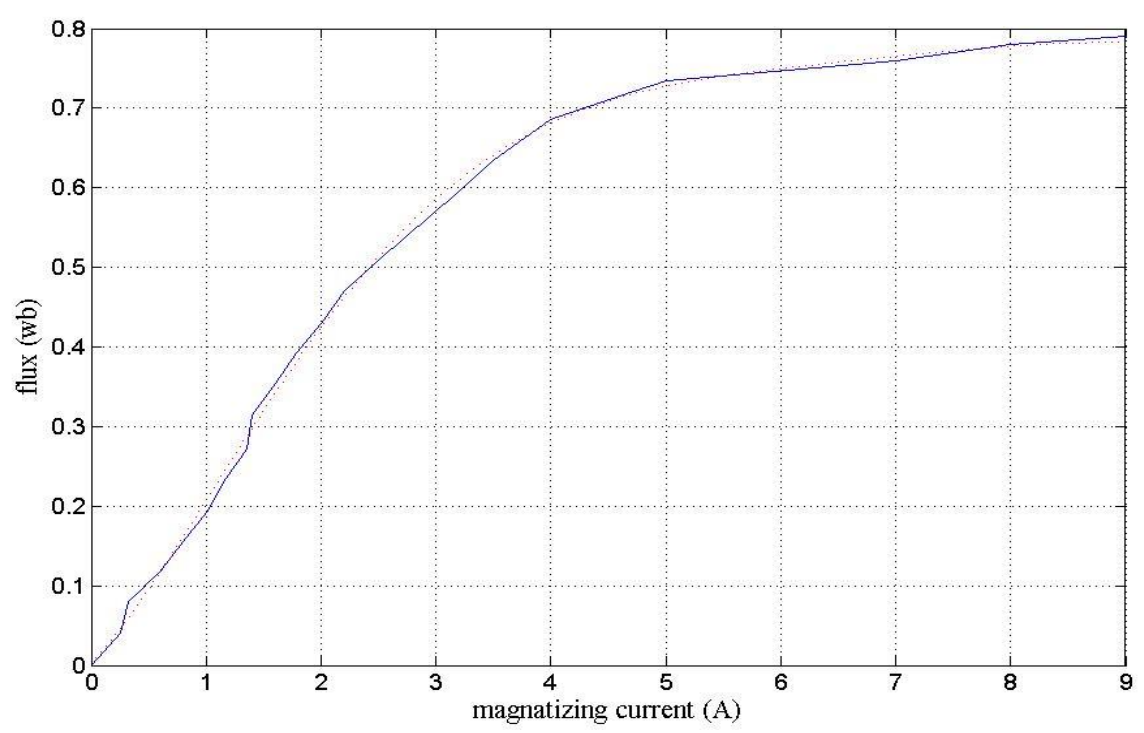

Figure App. I: Magnetizing curve of the induction machine used in simulation. 


\section{REFERENCES:}

1. Cyril Spiteri Staines, Greg M. Asher, and Mark Sumner, "Rotor-position estimation for induction machines at zero and low frequency utilizing zerosequence currents". IEEE Trans. Ind. Applic., 42 (1) (2006), pp. 105-112.

2. Marko Hinkkanen, Veli-Matti Leppänen, and Jorma Luomi, "Flux observer enhanced with low-frequency signal injection allowing sensorless zero-frequency operation of inductionmotors". IEEE Trans. Ind. Applic., 41 (1) (2005), pp. 52-59.

3. C. Ilas, A. Bettini, L. Ferraris, G. Griva, and F. Profumo, "Comparison of different schemes without shaft sensors for field oriented control drives". IEEE Conf. in the Ind. Electr. (IECON'94), 3 (1994), pp. 1579-1588.

4. F.Z. Peng, T. Fukao, "Robust speed identification for speed-sensorless vector control of induction motors". IEEE Trans. Ind. Applic., 30 (5), 1994, pp. 1234 1240 .

5. M. Rashed and A.F. Stronach, "A stable back-EMF MRAS-based sensorless low speed induction motor drive insensitive to stator resistance variation". IEE Proc. Electr. Power Applic., 151 (6) (2004), pp. 685-693.

6. Chul-Woo Park and Woo-Hyen Kwon, "Simple and robust speed sensorless vector control of induction motor using stator current based MRAC". Electric Power Systems Research, Elsevier, 71 (2004), pp. 257-266.

7. G. Garcia Soto, E. Mendes and A. Razek, "Reduced-order observers for rotor flux, rotor resistance and speed estimation for vector controlled induction motor drives using the extended Kalman filter technique". IEE Proc.-Electr. Power Applic., 146 (3)( 1999), pp. 282-288.

8. Surapong Suwankawin and Somboon Sangwongwanich, "Design strategy of an adaptive full-order observer for speed-sensorless induction-motor drives tracking performance and stabilization". IEEE Trans. Ind. Electr., 53 (1) (2006), pp. 96-119.

9. J. R. Heredia, F. Perez Hidalgo, and J. L. Duran Paz, "Sensorless Control of Induction Motors by Artificial Neural Networks". IEEE Trans. Ind. Electr., 48 (5) (2001), pp. 1038-1040.

10. Marko Hinkkanen, "Analysis and design of full-order flux observers for sensorless induction motors." IEEE Trans. Ind. Electr., 51 (5) (2004), pp. 1033-1340.

11. M. S. Zaky, M. M. Khater, H. Yasin, and S. S. Shokralla, A. El-Sabbe, "Speedsensorless control of induction motor drives (Review Paper)", Engineering Research Journal (ERJ), Faculty of Engineering, Minoufiya University, Egypt, Vol. 30, No. 4, October 2007, PP. 433-444.

12. Emil Levi, and Mingyu Wang, "Online Identification of the Mutual Inductance for Vector Controlled Induction Motor Drives," IEEE Trans. on Energy Conversion, Vol. 18, No. 2, June 2003, pp. 299-305.

13. Emil Levi, Matija Sokola, and Slobodan N. Vukosavic, "A method for magnetizing curve identification in rotor flux oriented induction machines," IEEE Trans. On Energy Conversion, Vol. 15, No. 2, June 2000, pp. 157-162.

14. E.Levi, S.Vukosavic, V.Vuckovic; "Saturation compensation schemes for vector controlled induction motor drives", IEEE Power Electronics Specialists Conference PESC, San Antonio, TX, 1990, pp. 591-598.

15. P. Vas, and M. Alakula, "Field oriented control of saturated induction machines," IEEE Trans. Ener. Corw., vol. 5, no. 1, pp. 218-223, 1990. 
16. M. S. Zaky, M. M. Khater, H. Yasin, and S. S. Shokralla, "Magnetizing inductance identification algorithm for operation of speed-sensorless induction motor drives in the field weakening region", IEEE Conf. MEPCON, Aswan, Egypt, 2008, PP. 103-108.

17. C. Schauder, "Adaptive speed identification for vector control of induction motor without rotational transducers", IEEE Trans. Ind. Appl. 28 (5) (1992) 1054-1061.

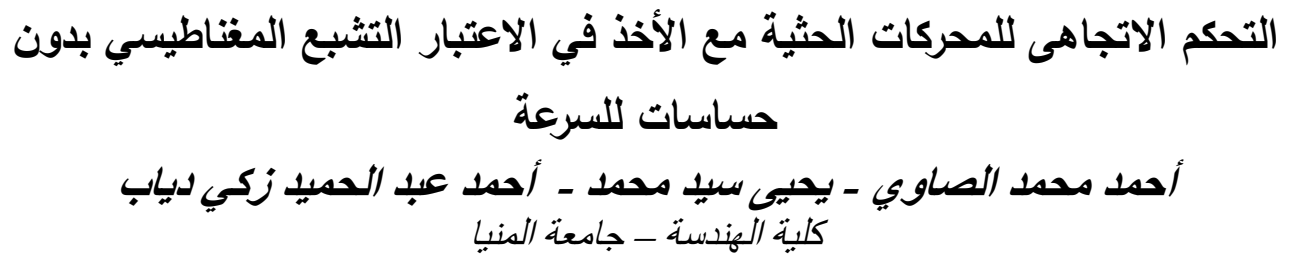

ملخص- الهدف من البحث هو تقييم السرعة للتحكم الأتجاهى للمحرك الحثى مع الأخذ في الاعتبار

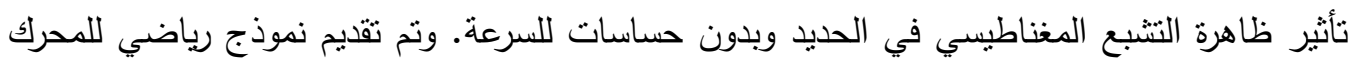

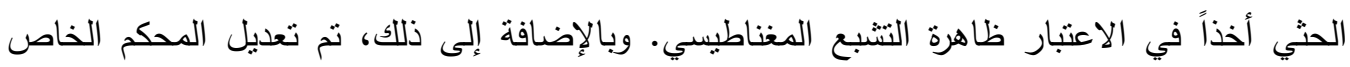

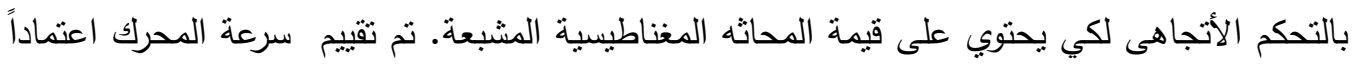
على النموذج المرجعي للنظام الملائم (Model Reference Adaptive System) للتحكم في السرعة في مدى واسع للتتغيل. وقد تم أخذ ظاهرة التتبع المغناطبسي في الاعتبار بعمل مقدر لقيمة المحاثه المغناطيسية للعمل مع النظام. وتم عرض نتائج باستخدام الحاسوب لتوضيح مدى قدرة الطريقة المقترحة للنطبيق. وقد برهنت النتائج المعروضة على أن خواص نظام المحرك جيدة في الحالة الديناميكية والاستاتيكية وهذا يؤكد قدرة الطريقة على تحقيق الأغراض المطلوبة. 